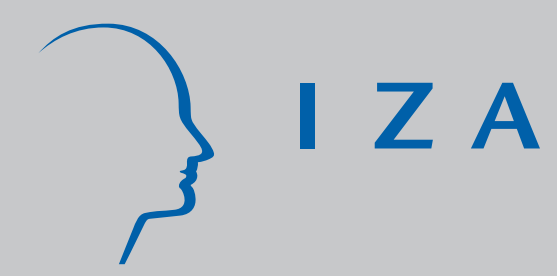

IZA DP No. 528

\title{
Arbitration and Mediation: An Economic
} Perspective

Paola Manzini

Marco Mariotti

J uly 2002 


\title{
Arbitration and Mediation: An Economic Perspective
}

\author{
Paola Manzini \\ Queen Mary, University of London and IZA Bonn
}

\author{
Marco Mariotti
}

University of Exeter

Discussion Paper No. 528
July 2002

IZA

P.O. Box 7240

D-53072 Bonn

Germany

Tel.: +49-228-3894-0

Fax: +49-228-3894-210

Email: iza@iza.org

This Discussion Paper is issued within the framework of IZA's research area The Welfare State and Labor Markets. Any opinions expressed here are those of the author(s) and not those of the institute. Research disseminated by IZA may include views on policy, but the institute itself takes no institutional policy positions.

The Institute for the Study of Labor (IZA) in Bonn is a local and virtual international research center and a place of communication between science, politics and business. IZA is an independent, nonprofit limited liability company (Gesellschaft mit beschränkter Haftung) supported by the Deutsche Post AG. The center is associated with the University of Bonn and offers a stimulating research environment through its research networks, research support, and visitors and doctoral programs. IZA engages in (i) original and internationally competitive research in all fields of labor economics, (ii) development of policy concepts, and (iii) dissemination of research results and concepts to the interested public. The current research program deals with (1) mobility and flexibility of labor, (2) internationalization of labor markets, (3) the welfare state and labor markets, (4) labor markets in transition countries, (5) the future of labor, (6) evaluation of labor market policies and projects and (7) general labor economics.

IZA Discussion Papers often represent preliminary work and are circulated to encourage discussion. Citation of such a paper should account for its provisional character. A revised version may be available on the IZA website (www.iza.org) or directly from the author. 
IZA Discussion Paper No. 528

July 2002

\section{ABSTRACT}

\section{Arbitration and Mediation: An Economic Perspective*}

This paper deals with the effects that intermediation has on strategic behaviour in negotiations. To this end, we use the tools of game theory to analyse how different institutional settings can provide specific strategic incentives and thereby condition the outcome of negotiations. We concentrate on some very recent contributions which have addressed gaps in this literature and stress the economic institution behind some predicted behaviours.

JEL Classification: J52

Keywords: arbitration, mediation, bargaining

Paola Manzini

Department of Economics

Queen Mary, University of London

Mile End Road

London E1 4NS

U.K.

Tel.: +442078825083

Fax: +44 2089833580

Email: p.manzini@qmul.ac.uk

\footnotetext{
* Manzini acknowledges financial support from ESRC grant R000223438.
} 


\section{Introduction}

Bargaining theory researches the methods, procedures and processes through which groups of individuals settle disagreement. The structure, conduct and outcome of negotiations is obviously of critical importance for the social sciences, and economics in particular. Bargaining among individuals, firms, groups, political parties and nations spans the social, political and economic landscape. In addition, a widespread phenomenon is the (voluntary) call for the (possibly costly) intervention of intermediaries in resolving the dispute, despite the bargainers' complete freedom to lawfully bypass any institutional mechanism for dispute resolution if they so choose. Arbitration is one typical instance, and many others abound in the field of international relations, from the role of the US in Israel-Palestine negotiations to that of the British and Irish Governments in those between Unionists and Republicans in Northern Ireland, just to mention a couple.

The backdrop of negotiations is crucially important in determining the behaviour of the negotiating parties. Although the role of third parties in promoting agreement and efficiency in bargaining is informally a widely accepted fact, there is no widely accepted theory of why and how this positive role is played. Curiously very little research has been carried out on the role of third parties in settling disputes (on this point, see Muthoo (1999)).

This paper deals with the effects that intermediation has on strategic behaviour in negotiations. To this end, we will use the tools of game theory to analyse such situations of strategic interaction ${ }^{1}$. We will not provide a comprehensive survey of the economic literature on arbitration; rather we will dwell on some very recent contributions which have addressed gaps in this literature and stress the economic intuition behind some predicted behaviours.

It is important to clarify terminology at the outset. In this paper we categorise the various form of third-party intermediation depending on what the answers to the following questions are:

\footnotetext{
${ }^{1}$ Game theory in general is a framework which relies on mathematical methods to study situations in which agents act strategically. In economics, bargaining theory is essentially a branch of game theory.
} 
1. Is the intermediary's proposed settlement binding?

2. Do the contending parties know what procedure the intermediary is going to rely upon?

3. Can any of the parties call in the intermediator, or is the consent of all parties required?

4. Can the intermediary vary the amount of resources which is potentially available?

The first important distinction to make is between those cases where the recommendation of the intermediary is binding, and those where it is not. In this paper we will refer to the former as arbitration, and to the latter as mediation ${ }^{2}$.

Regarding the second question above, consider that standard economic analysis generally proceeds by stripping the description of a situation down to its bare essentials, so as to be able to frame it and analyse it mathematically. In this way many features which may appear relevant in real life, but are not in terms of strategic incentives, are lost, and an arbiter or a mediator may well not be an individual at all. For instance, suppose that the custom is that in some specific type of disputes on commonly owned assets the issue is resolved by selling all assets on the open market and splitting the proceeds equally among the contendents. In this case, although the value of the assets is unknown before the sale, there is no uncertainty as to how the revenues are going to be divided among the contenders. Then, if such a custom were prevalent, you would not really need a physical person as an arbitrator for the dispute to be solved: the parties can simply invoke the custom: arbitration procedures in this case are tantamount to a mechanism, where the 'personal' element is in effect non essential.

The third important issue is whether the intermediary can be accessed unilaterally, or whether mutual consent is needed. For instance, in many US states the recourse to arbitration is required by law in those sectors where strike is restricted, and triggered

\footnotetext{
${ }^{2}$ Note that this is not yet standard in the economic literature, as some authors use arbitration to refer to non binding agreements (see e.g. Compte and Jehiel (1995))
} 
automatically in case of a stalemate. In Italian and $\mathrm{UK} \mathrm{law}^{3}$ arbitration can take place only with the agreement of the parties.

The fourth crucial feature mentioned above concerns whether the intermediary can inject extra resources in addition to those being haggled over. Note that in this case we are always in the realms of mediation, as we have defined an arbiter as someone (or some mechanism) which implements some division of resources already available. This time, then, the distinction we draw is between passive and active mediators, where by the latter term we refer to mediator with the power to add (or withdraw) resources from the negotiating table. This is typically the case in bilateral conflicts which impact on third parties outside the negotiations, such as in industrial disputes in sectors of public interest (e.g. transport, energy, health, etc.), or international relations (e.g. the Israel-Palestine conflict has impact on world stability).

An additional issue which embraces all of the points raised above concerns information, namely whether or not the procedure in case of intermediation is known in advance or not. If it is, then parties can anticipate the effect of their behaviour. For instance, in final offer arbitration the arbiter is restricted in his choice of settlement, in that he can only choose one of the final proposals put forward by the arguing parties - as is well known, this is aimed at reducing the occurrence of extreme demands from the contenders ('the chilling effect'). If instead there is uncertainty as to what the preferences of the arbiter/mediator or the opponent, then the contenders have to engage in a considerable amount of guesswork. As we will see, incomplete information of this kind complicates the analysis considerably, and is less helpful in predicting or suggesting an optimal outcome.

In the rest of the paper we focus for simplicity on bilateral negotiations in the presence of intermediaries (either mediators or arbiters), in correspondence with the four features highlighted above. Indeed, two-sided bargaining is the only setting where these issues have been dealt with formally. Still, this should be no great limitation, as we will see that a great deal of real life negotiations can be easily accommodated within this frame

\footnotetext{
${ }^{3}$ In the UK, "[Arbitration] is method of resolving disputes between parties without recourse to the law. It is voluntary, and the procedures have to be agreed by both parties beforehand" (see Kennerley (1994)).
} 
of reference. We start by introducing the alternating offers model, which has established itself as the archetypal benchmark framework to model negotiations in economics. Section 3 deals with the strategic incentives that arbitration presents to the negotiating parties, where in line with the discussion above we distinguish between unilateral and consent arbitration. We turn to mediation in section 4 , while in section 5 we provide an overview of the issues involved when agents are not perfectly informed about some relevant features of the negotiating environment. Section 6 concludes.

\section{A benchmark model of negotiations: alternating offers}

Economists use extremely stylised models to analyse bargaining situations. The standard model in its basic version, from which most of the rest of bargaining literature departs, is due to Rubinstein (1982). The Rubinstein idea is mathematically complex, but it can be understood by proceeding through successive approximations. Imagine that two parties must divide the proceeds of the sale of a house amounting to $£ 100,000$. What procedure could they use to agree on a division? Consider first an extreme possibility, which goes under the name of Ultimatum Game: party A proposes a division to party B. Party B can either accept of reject the proposal by A. If he accepts, the 'game' ends with the agreed division. If party $\mathrm{B}$ rejects, there is irreconcilable disagreement, in which case we make the draconian assumption that all of the gains from the sale of the house will be lost. It is easy to see that, if the bargainers are rational, party A will be able to appropriate virtually the entire sum of $£ 100,000$. This is because party B will accept any proposal yielding him a sum greater than zero. What else could he do, given that in case of rejection he will get nothing? Thus, if we rule out irrational behaviour (e.g. spite), party B will grudgingly accept the final settlement. Now modify this procedure to make it just a little more realistic, by allowing party B to make a counterproposal in case of rejection. If party $\mathrm{A}$ rejects the counterproposal, the negotiations end in the same way as above. Assume that the delay and protraction of negotiations caused by a rejection is costly to the parties, and for simplicity express this cost as a percentage 
reduction of the value of the deal, say 1 percent for definiteness. What is the outcome of this enriched model? Reason backwards: if negotiations reached the second stage, with party B making a final take-it-or-leave-it proposal, party A will be in the same position as B was in the first stage of the previous simpler game, and he will accept any arbitrarily small amount. So, if negotiations reached the second stage, $B$ would be able at that stage to extract close to the entire remaining value. Since we assumed that the value reduces at a rate of 1 percent, the remaining value is $£ 99,000$, and $B$ could obtain virtually all of it, leaving nothing to A. But anticipating this, A in the first stage could avoid the delay by offering $£ 99,000$ to B. B would accept this offer, because he could do no better than that by rejecting. Therefore offering $£ 99,000$ would be a smart move for A, because he could secure at least $£ 1000$ (the residual of the unreduced value). The model can now be enriched further by allowing A to make a counter-counterproposal to B, so that the negotiations could potentially reach a third stage, with the value reduced by a further 1 percent to $£(99,000-(0.01) 99,000)=98,010$. By using the same type of reasoning as before one can see that this time the agreement, still in the first stage, will assign A the sum of $£ 98,010$.

In real life, unlike in the examples above, negotiations normally do not have a fixed number of stages. In Rubinstein's 'alternating offers model', negotiations are conducted with the parties alternating in making offers as explained, but the they are always allowed to make a counterproposal to an offer received. Neither party is ever in a position to make a take-it-or-leave-it offer, and negotiations may potentially go on indefinitely, although that would be a very bad outcome for the parties because in that case the value of an agreement in the indefinitely far future would be reduced to zero. By pushing the previous type of considerations to the limit, it is possible to show that there is only one possible outcome for the negotiations (assuming players are rational) with agreement reached at the first stage on a division that depends on the parameters of the model, notably the rate of depreciation of the asset. Typically however part of the bargaining power coming from the take-it-or-leave-it argument articulated above is retained by the first agent that can table a proposal. This feature is referred to in the literature as 'first mover advantage'. For example with the one percent rate assumed before, the division 
would assign approximately $£ 50,251$ to the party who has the initiative by making the first proposal. Furthermore, the party who cares less about the rate of depreciation of the asset stands to gain in negotiations: as he suffers relatively less if the asset depreciates following disagreement, he is in a stronger bargaining position than his opponent.

The interesting feature of the benchmark Rubinstein model is that the outcome is efficient: there is no unnecessary costly delay. This feature is robust to some changes of the model and not to others (such as incomplete information). This provides a very useful guide to understand the factors that may hamper the attainment of an efficient outcome of negotiations ${ }^{4}$. With regard to the present paper, the interest of the benchmark model is that it provides a basis from which to start when analysing the effect of arbitration in bargaining.

\section{Incentives for bargainers when Arbitration is pos- sible}

Our first stab at the problem is to compare the situation where either party can unilaterally can call in an arbitrator, to the situation where in order to call in a third party for help, negotiators must 'agree to disagree', and exiting the current negotiations to switch to a different type of relationship requires unanimous consent. In order to focus exclusively on this issue we assume that the outcome of arbitration, should it be used, is known in advance and with certainty by the parties. There is thus no question of one party exploiting its superior information, or of parties using or not using arbitration on the basis of 'wrong' (that is, excessively optimistic or pessimistic) beliefs as to the decision of the arbitrator. We stress that this does not deny that in practice such psychological features are of relevance: the assumption is merely a methodological device which allows one to isolate the effects of the specific factor of interest at this stage.

The first thing to understand when considering the behaviour of sophisticated negotiators is that if proposing to use the services of an arbitrator is an available option to the

\footnotetext{
${ }^{4}$ This model has been enriched in many different directions. See e.g. Muthoo (1999) for an excellent introduction.
} 
parties, this option will be used strategically within the negotiating process. That is to say, proposing to go to arbitration should not be seen as an option of last resort, which has relevance only when all other negotiating tactics fail. Rather, it should be treated in the same manner as any other available bargaining move or proposal, as a crucial component of an overall bargaining tactic. The issue is thus to examine the strategic incentives that arbitration offers to the parties.

\subsection{Unilateral arbitration}

This situation can be conveniently modeled by giving to each party, in the stylised model of alternating offers, the option to call in an arbitrator at any moment in the negotiations if they are unhappy with the opponent's proposal. Going to arbitration overcomes impasses in negotiations but may be subject to other costs (e.g. the arbitrator's fee). The outcome of such a negotiation game is governed by a well-known general principle of bargaining theory, called the outside option principle (see Binmore et al. (1989), Binmore et al. (1986)). One might at first blush suppose that the party who stands to gain more from arbitration will be able to appropriate this advantage by using arbitration as a threat in the course of negotiations. In fact, the crucial insight of game theory is that such a threat will be empty unless the arbitrated outcome is superior to the outcome of the negotiations conducted (rationally) without an arbitrator (the standard outcome). In other words, what matters is not the relative advantage of the negotiators in arbitration, but the relationship between the arbitrated outcome and the standard outcome. It may well be the case that one party stands to get more in arbitration than the other, yet less than what it would get in straight negotiations: in such a case there is no scope whatsoever for a strategic use of arbitration. Any threat of recurring to arbitration would not be credible, and therefore disregarded: the result of negotiations with the possibility of arbitration will be exactly the same as the result of negotiations without such a possibility ${ }^{5}$.

On the other hand, if one of the parties does stand to gain more from arbitration than in the standard outcome, then the arbitrated outcome will drive the negotiated outcome completely: the party who stands to gain less from arbitration than the standard outcome

\footnotetext{
${ }^{5}$ Again, rememeber that we are ignoring 'psychological' effects and the like.
} 
(and there must be at least one such a party if the arbitrator cannot add resources to the negotiations) can do no better than to concede to the opponent what he would get in arbitration.

So consider for example the $£ 100,000$ house proceeds division problem and suppose that the negotiating framework allows each party to call in an arbitrator. The overall arbitration costs are $5 \%$ of the value of the deal and they are evenly split between the parties. Suppose it is commonly known that the arbitrator would assign $55 \%$ of the proceeds (net of arbitration costs) in favour of part A and $45 \%$ in favour of party B. Whether and how A can exploit this advantage strategically in negotiations depends on what the outcome of hypothetical negotiations conducted without the possibility of calling in an arbitrator would be. If in those hypothetical negotiations he would have got, say, $£ 52,500$, then negotiations in the shadow of arbitration would proceed exactly in the same manner as if arbitration was not available. No threat of calling in the arbitrator would ever be observed. Suppose A proposed a division assigning him, say, 53,000, accompanying this proposal with the threat that, if it was rejected, he would call in the arbitrator. Then B would simply ignore the threat and insist on conceding just $£ 52,500$ to A. The threat is not credible because $\mathrm{A}$, faced with the choice between $£ 52,500$ and the threatened arbitrated outcome would not carry it out. With this knowledge, he will not even make it and avoid needless delays in negotiations. On the other hand, consider the case where in the hypothetical situation with no arbitration A would get $£ 52,000$. Then he should insist on getting $£ 52,250$ and back this proposal with the threat of calling in the arbitrator. This threat by A would be credible because any alternative proposal by B assigning him a smaller portion of the proceeds would be inferior for A to the arbitrated outcome net of costs. Observe that in both cases in the course of our reasoning we are comparing the arbitrated outcome to the hypothetical negotiated outcome, and we are not comparing the relative amounts the two parties would get with arbitration.

It is also important to observe that in any case there is no need to resort to arbitration. In this stylised model, arbitration would never be observed (though in some cases it will drive the negotiated outcome). We understand from this, for example, that the size and content of the arbitrated outcome cannot on its own explain the frequency and recourse 
to arbitration. Other factors must be at play, such as the information available to parties the detailed structure of arbitration, and so on. ${ }^{6}$

\subsection{Consent arbitration}

In other situations both players must give their consent before the arbitrator is called in. This is the case in several institutional contexts. For example in the UK labor disputes are resolved by final offer arbitration (FOA) only with the consent of both parties (e.g. Milner (1993)). We can glean some insight into this type of situation by adapting again the basic framework of alternating offers, as done in Manzini and Mariotti (2001). In this case the negotiators may propose to call in an arbitrator at any moment in the negotiations if they are unhappy with the opponent's offer. For the arbitrator to be actually called in one needs the consent of the other party. One might think that since one of the parties is bound to lose from arbitration (compared to the outcome of negotiations without arbitration) and since both parties have veto power on calling in the arbitrator, the possibility of arbitration will be completely irrelevant in this case: the losing party will always veto arbitration. In fact, the strategic situation is more complex than that and a deeper analysis belies simple-minded intuition.

Focussing for simplicity on the case where arbitration costs are negligible ${ }^{7}$, it turns out that the intuitive outcome described above is just one possibility. Another possibility is that the negotiators will agree on an outcome identical to the one that is expected in arbitration, much as in one of the cases discussed above in the context of unilateral arbitration. This means that the veto power of the negotiator who stands to lose from arbitration ('the Loser') may be merely apparent and become completely vacuous in practice. The strategic force sustaining this situation is for the party who gains for arbitration

\footnotetext{
${ }^{6}$ Compte and Jehiel (1995) introduce a rather different model, in which the parties alternate in making concessions and there is an exogenous probability of breakdown, as well as an exogenous probability that arbitration is triggered automatically, in which case the decision of the arbitrator depends on the concessions up to that moment. The interesting feature is that delayed, and hence inefficient, agreements can be supported as the unique possible outcome unless the arbitrator is called in immediately.

${ }^{7}$ See Manzini and Mariotti (2001) for a complete analysis.
} 
('the Winner') to 'commit' itself $^{8}$ never to accept less than the value of the arbitrated outcome in negotiations, and to back this up by proposing to call in the arbitrator every time the Loser's bargaining proposal is unsatisfactory. In such a situation, the Loser can do no better than to accept arbitration, given the Winner's commitment. But then, it would be irrational for the Loser to even begin asking for more than the arbitrated outcome, incurring unnecessary costly delays in negotiations. This type of outcome can occur whenever the arbitration costs are not too high compared to negotiation costs. Also, it is possible to show ${ }^{9}$ that by using more complex bargaining tactics all the intermediate divisions between the two just described are possible outcomes of the negotiations.

To illustrate with the house example, suppose the outcome of negotiations without arbitration was a division assigning $£ 55,000$ to party $\mathrm{A}$ and $£ 45,000$ to party $\mathrm{B}$, whereas the common expectations are that an arbitrator would decide on a fifty-fifty division. Then in one extreme case it may happen that party $\mathrm{A}$ will manage to veto all attempts by $\mathrm{B}$ to get more than 45,000 . In this case negotiations will proceed with the players ignoring the possibility of arbitration altogether. But, by employing the negotiating commitment tactic just discussed, B may succeed in obtaining $£ 50,000$ in negotiations. By using more complex tactics, all agreements yielding player A an amount between $£ 55,000$ and $£ 50,0000$ may emerge as an outcome of negotiations.

Recently, Peña (2002) has combined the relevant features of the models by Manzini and Mariotti (2001) and Compte and Jehiel (1995) mentioned before, considering a framework of alternating concessions and consent arbitration. She finds that the results of Compte and Jehiel (1995) are dramatically altered, in the sense that inefficient delays are eliminated. However it may happen that the parties do not resort to arbitration even when it would be efficient to do so.

\footnotetext{
${ }^{8}$ Here 'commitment' is not used in (game theoretic) technical sense. If so, it would mean that the party takes a stand, and never looks back, somehow tying its hands forever. For the tactics described in the main text, instead, it is always optimal for the negotiator to insist on obtaining at least an amount equal to the arbitrated one, reiterating his stance every time, rather than taking it once and for all. In game theory parlance, this plan of action would constitute and 'equilibrium strategy'.

${ }^{9}$ See Manzini and Mariotti (2001) for details.
} 


\section{Incentives for bargainers when Mediation is possi- ble}

As specified before, we use the term mediation for those 'refereed' negotiations where, unlike with arbitration, parties do not have to commit ex ante to accept any settlement the mediator will put forward. In this sense, the mediator has an advisory role, and his or her suggestions may be accepted or rejected by either or both the negotiating sides. Passive mediators can only suggest a possible resolution. Thus, they can play a meaningful role only inasmuch as the contenders have some private information that they are adamant not to disclose to the other side for fear that this will worsen their bargaining position. The mediator is in this case a facilitator who has to gain the confidence of both sides so as to access to their private information in an effort to find some common ground. Once this situation is bared down to its essential, the mediator can be modeled as some sort of impersonal mechanism, a kind of 'clearing house' that can help parties 'get to yes'. For instance, in Jarque et al. (2001), the mediator collects the proposals that the two sides make, and announces that an agreement has been reached only if the two proposals are compatible. In this framework, assuming that delays are costly, each side is aware that early agreement can be obtained only at the cost of a large concession. Thus both sides take their time to give in, providing a rationale for delays.

More interesting in our opinion is to investigate the strategic incentives for bargainers once an active mediator is present. Recall that in this case the intermediary has a stake in the negotiations. For instance, industrial conflict which result in the disruption of essential services (e.g. transport, energy, health), whether publicly or privately provided, has a substantial knock-on effect on the public at large, and in turn, on the government. Such third parties, though affected by the dispute, and interested in the resolution of the conflict, are unable to impose an agreement upon the contending bargainers ${ }^{10}$. Indeed, it is the fact that stakeholders can lose out from conflict elsewhere which creates the incentive

\footnotetext{
${ }^{10}$ Note that in the case of either arbitration or passive mediation, the intermediary'payoff is independent of whether or not the two stalling parties strike a deal. See for instance Compte and Jehiel (1995), Jarque et al. (2001), Manzini and Mariotti (2001), Ponsatí (2001) and Wilson (2000).
} 
and opportunity to throw in the conflict additional resources to promote agreement. That is, posing as an active mediator is a desirable strategy for the stakeholder, provided, of course, that the overall contribution does not exceed what would be lost in case of a stalemate!

It is important to note that the presence of an active mediator in negotiations can create incentives for the negotiating parties which produce perverse effects. To fix ideas, consider first a very simplified setup where at the outset the mediator proposes a settlement of the original conflict plus some additional contributions from his own stake. If both bargainers accept, negotiations end in agreement. If any of the two bargainers rejects, then there is an additional and terminal round of negotiations, where the (first) rejecting bargainer can make a final take-it-or-leave-it offer to the other bargainer, after which the game either ends in agreement (if the proposal is accepted), or in disagreement (if the proposal is rejected). Then, the outcome of these negotiations must be that agreement is only achieved in the second round of negotiations, that is, with delay.

To see this, note that any of the bargainer can reject the initial proposal and then move on to successfully claim everything in the second and final round - as in the ultimatum game discussed in section 2. Consequently, any initial proposal by the mediator will be acceptable to the bargainers only if it removes their incentive to reject, i.e. only if it provides each of them with an amount of resources equivalent to what they could otherwise obtain in the next round (i.e. everything) net of transactions costs - that is, twice as many resources originally available, net of costs.

As a necessity, then, provided transactions costs are not excessively high, the only way that this settlement can be agreed upon at the outset is if the mediator concedes part of his own stake, to make up for the shortfall in the original resources. However, this may either not be possible, for instance because the stake of the mediator is not large enough; or create additional incentives for the bargainers to reject. The latter is the case if the commitment made by the mediator in his first proposal is binding. In this case, then both bargainers always have an incentive to reject any settlement, and make the final take-it-or-leave-it offer, still obtaining the contribution promised by the mediator. So, any positive initial contribution would result in agreement in the second round. On 
the other hand, if the mediator made no contribution, once again at least one of the bargainers would have an incentive to reject and obtain everything in the final round. As a consequence, in any event these negotiations would result in delayed agreement.

The argument above shows that even in a very simple bargaining framework the presence of a generous (i.e. committed) mediator may have the (apparently) counterintuitive effect of generating inefficiencies. On the other hand, a slight modification of the structure above can overcome delays in agreement if the mediator is sufficiently 'mean', in the sense that not only is he not generous (contributions which are not immediately accepted are withdrawn), but he has to be sufficiently 'greedy' - in the sense that he has to be sufficiently fearful of the costs resulting from disagreement. Suppose then that the mediator's opening contributions are 'proposal related', so that if the opening settlement is turned down, the proposed contributions no longer stand. Under this 'no commitment' assumption, the incentive for bargainers to reject the opening proposal and go for the take-it-or-leave-it final phase disappears. Thus, it is now possible for the mediator to make an opening proposal that will be accepted. Yet again, would it be optimal for the mediator to do so? After all, the contending parties would agree in the end, in which case the mediator would get away with not giving out anything. Thus, provided delay is not too costly (for instance because of the political consequences of perceived inaction), it may make sense for the mediator to put forward a 'silly' proposal so as to encourage at least one of the bargainers to turn it down, thereby causing delayed agreement once more.

This example is surely too stylised to be readily fitted to a wide variety of applications. Still, it is instrumental to make the point that the effect of mediation on the outcome of negotiations is by no means straightforward: although very simple, the structure described above highlights the interplay of the bargainers' and the mediator's strategic incentives in negotiations, and their effect on the final outcome, which, as shown, do not necessarily induce the gain in efficiency that one would hope for. Indeed, in the setup discussed the presence of a mediator introduces inefficiencies where there would be none.

So let us turn now to a still stylised but more sensible negotiating framework ${ }^{11}$.

\footnotetext{
${ }^{11}$ The next section provides a non technical account of the material in Manzini and Ponsatí (2001).
} 


\subsection{Public sector bargaining}

As we saw above, the sheer possibility that the stakeholder (i.e. the government) may intervene in negotiations creates the potential for delays, in the hope to pressurise the government into conceding extra resources. This situation is in apparent contradiction with the tendency of government to devolve rights and privatise a number of previously publicly run services over the past three decades. Since the government remains a stakeholder, contending parties (e.g. management and union in the privatised utility) have an incentive to haggle so as to induce the government to intervene with handouts. Then, why would a stakeholder want to change the 'rules of the game' to an inefficient and costly negotiating framework ${ }^{12}$ ?

Below we present a simple framework to deal with this issue, which shows that stakeholders are usually willing to make contributions to promote agreement, and as expected this willingness may backfire and become the source of severe inefficiency. However, and more surprisingly, for a wide range of cases this outcome is better for the stakeholdergovernment than a situation in which it is a bargainer itself.

The intuition for this result is straightforward. Delays are harmful for all of the agents involved in negotiations; however, in negotiations involving three sides (e.g. employer, employees and the government), the management and the stakeholder can join forces and secure as a coalition an agreement which is more advantageous than what they would otherwise obtain as a single negotiator in bilateral bargaining with the employees union.

In order to study the effects produced by a mediator in negotiations, one can adapt the benchmark model of section 2 by adding a third player, the stakeholder-mediator. Now each agent can not only put forward a proposed settlement, but also claim (if one of the original negotiators) or put forward (if the mediator) a pair of 'gifts' to each of the original parties in the dispute. Note well that the crucial point is the asymmetry in this trilateral

\footnotetext{
${ }^{12}$ It is very difficult for a stakeholder to limit its involvment by fixing the maximum contribution available to avert stalemate in negotiations. Besides the potential political cost, it would be a noncredible commitment, as the stakeholder has all of its stake to lose while the two bargainers haggle. This fact is mirored in real negotiations - e.g. in the UK the Fire service threatened strike of 1980 was averted by awarding a $18.8 \%$ rise, thus breaking the Conservative Government's guidlines for the public sector. See Morris (1986).
} 
negotiations: while the original negotiating parties (henceforth referred to as bargainers) can make a claim which involves both the original set of resources and the stake of the mediator, the latter can only give up resources, but obviously has no right over the issues being disputed. This is the crucial aspect which distinguishes the 'stakeholder game' from standard three players negotiations, and which creates the incentive for decentralisation, i.e., one agent active in bilateral bargaining has the incentive, if he can, to devolve his negotiating rights to a representative, and remain involved only as a stakeholder. This incentive comes from the fact that the composite player so obtained (i.e. stakeholder + delegated bargainer) can achieve an overall payoff which is higher than if he were bargaining centrally over the same amount of resources. Obviously, this exercise must be carried out with care, as one would otherwise run the risk of increasing artificially the bargaining power of the delegator-delegate pair. Take for instance an initial bargaining situation where the protocol assigns to each agent the right to make a proposal with equal probability ${ }^{13}$ of $\frac{1}{2}$, and suppose one of the two original parties where to delegate irrevocably his own negotiating rights to a third agent. If the negotiating protocol in the resulting stakeholder game still assigned equal probability to each agent making a proposal, this new arrangement would be most unfair to the remaining original bargainer, as the probability to be first to table a proposal for the original bargainer would only be $\frac{1}{3}$.

However, even if decentralisation were to take place without eating into the initial bargaining position of the remaining bargainer, there can still be the incentive for decentralisation of negotiations. In particular, suppose that the stake of the stakeholder after delegation is small relative to the overall resources under contention. This clearly limits the ability of the stakeholder to contribute additional resources to the other two contenders, and it may be optimal for the stakeholder actually to contribute nothing, and let the other two contenders to fight it out. Thus, the aggregation of the stake and the share for the delegate bargainer exceeds the payoff that the stakeholder could have

\footnotetext{
${ }^{13}$ The bargaining protocol with probabilistic first mover is known in the literature as 'random proposer' model. If this modification where applied to the benchmark model introduced in section 2, optimal behaviour would predict agreement on the 'fifty-fifty' division of the asset.
} 
obtained in bilateral negotiations, had he not called himself out.

Note that the delegation in this context is an irreversible act, and that the delegate for that matter may have preferences which are completely opposite to those of the stakeholder. For instance, in the UK Fire Service industrial dispute in 1980, the Conservative Party was in Government, but it was not the direct employer for the Fire Service. A pay increase of $18.8 \%$ was reached when the Labour party (in opposition) gained control of the employer's side of the National Joint Council (see Morris (1986)).

Thus, the stakeholder model is suited both to provide a positive analysis of negotiations which include an unwilling, external onlooker, and to rationalise situations where the stakeholder irreversibly modifies the 'rules of the game'.

\section{Information}

All we have said so far has assumed that parties were perfectly and completely informed about the relevant features of the situation they were involved in. In economics agents are imperfectly informed when they are aware of opponents' preferences, but choose their plan of action ${ }^{14}$ ignoring what the other agents have chosen to do. In a way, it is as if they were choosing their actions simultaneously as their opponents. The class of games of imperfect information does not pose difficult technical challenges, but has the by-product that optimal behaviour in this setup may produce some unsavoury outcomes. Because at the time they choose their strategy agents do not know the choice of their opponents, they will have to base their choice on their expectation of what the other agents will do - as we will see, this can lead to potentially disastrous outcomes. For instance, think of bank runs: they can be thought of as resulting from the expectation each agent has that other customers will withdraw their funds form the bank, leaving nothing for the others

\footnotetext{
${ }^{14}$ This is termed strategy in the jargon of game theory. This term has a rather different meaning from natural language, and in technical sense a strategy is a complete contingent plan of actions. One can think of a strategy as a very detailed list of instructions to be handed over to a representative, which has to specify what the representative should do in every possible occurence. One of the consequences of this definition which looks puzzling to the non-specialist is that a strategy must specify what to do even at stages of the game which could not have been reached had one followed the strategy up to that point.
} 
- as a consequence, everybody else will quite rationally prefer to run themselves to the bank and withdraw their own savings. These 'pessimistic' expectations thereby lead to a collapse of the banking system. From the economist's perspective, this corresponds to an equilibrium outcome, as everybody is optimising his own behaviour given the (low) expectations he has of others. On the other hand, there is also the 'good' equilibrium where banks continue to thrive since everybody expects that everybody else expects that nobody will run to the bank, so that there is no reason for any agent to do so.

Not surprisingly, then, once imperfect information is added to negotiation models, multiple optimal agreements including many inefficient ones may arise. We clarify this point with an example ${ }^{15}$. Consider an industrial relations dispute where for instance a firm is threatening to close a plant based on resource constraints. This means that on the one hand the firm could do with a handout from the government, and on the other hand it would prefer a downward wage renegotiation with its workers. This setup can be viewed in the context of stakeholder games: the closure of the plant has an impact on the rest of the economy which guarantees that the government is an interested party.

In effect, here the management of the firm is involved in two sets of negotiations, one with the government over the handout, and one with the workers over wages, where both the government and the workers take their negotiating stance unaware of what is going on on the other negotiating table. Assuming that all parties prefer agreement to disagreement (which would result in the plant closure), and that they prefer to reach an agreement sooner rather than later, these composite negotiations end up predicting a variety of possible optimising behaviours, including inefficient ones where agreement is reached only after protracted haggling. The crucial point is that the two set of negotiations are interconnected, and the firm can condition its behaviour in one dispute on its behaviour in the other. Furthermore, because the successful resolution of the whole dispute depends on agreement in each of the two negotiations (the one over wages and the one over the government handout), neither the workforce nor the government can impose a resolution on their own, since they have no direct influence on the set of negotiations in which they are not involved. This is not the case for the firm, which can on its own accord either

\footnotetext{
${ }^{15}$ The discussion that follows is based on Manzini (2001).
} 
bring about a quick resolution, by conceding on both negotiating tables; or impose a drawn out process to both of the other sides, by insisting on obtaining the maximum concessions possible. Provided the gains from obtaining its most favoured alternative are sufficiently high, the latter may be an attractive prospect for the firm.

More challenging is to deal with situations where agents have incomplete information. This term defines those situations where agents are unsure about the preferences of their opponents. The usual way to model this situation in economics is to assume that agents can be of different 'types', and letting each party assign some probability to be facing each of the possible types. So for instance suppose that in the plant closure example above workers are unsure about how close to bankruptcy the firm actually is. The simplest way to deal with this is to assume that the firm can be of either a 'rich type' or a 'poor type', referring to the occurrences that the firm actually has large or little resources available.

Note that this type of technical stratagem can be used to deal with situations where the uncertainty is not about preferences, but for instance on the amount of resources available. So the fact that the firm is unsure as to the amount of resources available to the government can be modeled as having the government be of different types. Clearly, the optimal behaviour under incomplete information depends a lot on the probability distribution over types, and also on how agents update their beliefs as negotiations progress. For instance, the firm would expect a 'lean' government to hold firm on not conceding any contribution. On the other hand, a resource-rich government would also at least try to pretend that it has no cash to spare - then, as intuitively expected, delay might occur as a result of the firm probing the government to see whether it is really constrained on resources, or whether it is just pretending that it is. In this case, the possibility that an opponent is of several possible types is what accounts for protracted haggling.

Incomplete information issues make even very simple models highly intractable. Indeed, twenty years from its introduction there is still no general solution to the benchmark model of section 2 once incomplete information is introduced in the framework ${ }^{16}$. As we pointed out when dealing with arbitration in section 3, uncertainty about the settlement that will be chosen by the arbitrator is a possible reason why litigation occurs, whereby

\footnotetext{
${ }^{16}$ See Osborne and Rubinstein (1990) and Muthoo (1999) for a thorough introduction to these problems.
} 
both parties expect to get a higher share than the opponent. We are not aware of attempts to model these issues, as the expectation is that the added technical complications would not add much in terms of economic insight.

For this reason, a more successful way of addressing incomplete information in negotiation problems is to frame them as wars of attrition: briefly, each party has a preferred settlement (out of a set of possible ones), and parties insist on it until the other side concedes. Incomplete information can now be configured as the existence of several types of opponents, in correspondence of each possible settlement.

The stakeholder game can be re-framed along these lines ${ }^{17}$. So, now the original bargainers can either agree immediately on some settlement; or delay in the hope that the stakeholder (which loses out in case of disagreement) would intervene and inject additional resources. Bargainers are now uncertain as to the amount of resources that the stakeholder can part with (i.e. the 'type' of stakeholder). In this setup, as one would expect, there is an abundance of delayed agreements. However, as long as the stakeholder's stake is not too great, there are also optimising settlements in which the two litigants agree immediately with positive probability. This is the case when the two original contenders expect the stakeholder to 'play tough' and not intervene in case of a stalemate. If that is the case, then it makes sense for the bargainers not to haggle, and strike a deal straightaway. But then it is optimal for the stakeholder to dither, thereby pressurising the two bargainers into reaching a speedy conclusion.

Once more, the presence of a stakeholder may backfire and generate inefficiencies.

\section{Concluding remarks}

An important general observation that emerges from the analysis conducted in this paper is that, even when the option of going to arbitration is not used, it may well be that it has an impact on the outcome negotiated by the parties. That is, the outcome of negotiations would have been very different had arbitration not been available, and one should not infer from the lack of recourse to this option that it is irrelevant or useless. To argue in that

\footnotetext{
${ }^{17}$ The considerations that follow are based upon Manzini and Ponsatí (2001).
} 
way would mean committing a mistake of the same kind as saying that policing is useless after observing that no crime is committed; the point being that potential criminals alter their behaviour according to policing levels (perhaps to the point of committing no crime at all), just as bargainers alter their behaviour according to whether and how arbitration is available. As we have seen, in certain situations the mere presence of an arbitrator in the background of negotiations may entirely drive their outcome, even when no party can enforce arbitration on its own, and even when the arbitrator's services are not used.

Secondly, sometimes arbitration may increase the strategic complexity of the 'game' to the point where inefficient outcomes, with delays in agreement are introduced even in situations where they would not be possible in the absence of the possibility of arbitration.

Turning now to mediation, we have seen how stakeholder games are a useful tool to analyse situations where third parties have a vested interested in the resolution of some primary disputes. The incentives that the original contenders have to draw the stakeholder in the dispute can generate inefficiencies in the sense of delays. Moreover, the nature of the strategic incentives of the parties involved offer one possible explanation of why decentralisation (i.e. irrevocable delegation of bargaining rights) takes place.

Our focus in this paper has been to highlight how different institutional settings can provide specific strategic incentives and thereby condition the outcome of negotiations. To this end we have concentrated on two main setups for our analysis, consent arbitration and stakeholder games. These are novel ways of addressing these issues in economics, and we believe that they are flexible enough to be adapted to the study of other, richer negotiating environments. Still, we hope to have shown that even highly stylised frameworks give rise to complex interactions. For this reason, we have preferred to dwell more on two specific models rather than go down the route of providing a comprehensive but necessarily superficial survey of the forms of mediated negotiations analysed in economics, notably eschewing important institutions like final offer arbitration ${ }^{18}$. We hope that the gain from this approach has outweighed the cost.

\footnotetext{
${ }^{18}$ See Ashenfelter (1987), Ashenfelter and Bloom (1984), Ashenfelter and Currie (1990), Bloom and Cavanagh (1987), Brams and Merrill III (1983), Brams and Merrill III (1986), Farber and Bazerman (1986) just to cite a few, which provide further insights into the intitutional details and theoretical concepts on arbitration.
} 


\section{References}

O. Ashenfelter and D. E. Bloom. "Models of Arbitrator Behavior: Theory and Evidence". American Economic Review, 74:111-125, 1984.

O. Ashenfelter and J. Currie. "Negotiator Behavior and the Occurrence of Disputes". American Economic Review Papers and Proceedings, 80:416-420, 1990.

O. Ashenfelter. "Arbitrator Behavior". American Economic Review Papers and Proceedings, 77:342-346, 1987.

K. Binmore, A. Rubinstein, and A. Wolinsky. "The Nash Bargaining Solution in Economic Modelling". Rand Journal of Economics, 17:176-188, 1986.

K. Binmore, A. Shaked, and J. Sutton. "An Outside Option Experiment". Quarterly Journal of Economics, 104:753-770, 1989.

D. E. Bloom and C. L. Cavanagh. "Negotiator Behavior under Arbitration". American Economic Review Papers and Proceedings, 77:353-358, 1987.

S. J. Brams and S. Merrill III. "Equilibrium Strategies for Final-Offer Arbitration: There is No Median Convergence". Management Science, 29:927-41, 1983.

S. J. Brams and S. Merrill III. "Binding Versus Final-Offer Arbitration: A Combination is Best". Management Science, 32:1346-55, 1986.

O. Compte and P. Jehiel. "On the Role of Arbitration in Negotiations". mimeo, C.E.R.A.S.-E.N.P.C., 1995.

H. S. Farber and M. Bazerman. "The General Basis of Arbitrator Behavior: An Empirical Analysis of Conventional and Final-Offer Arbitration". Econometrica, 54:819-44, 1986.

X. Jarque, C. Ponsatí, and J. Sákovics. "Mediation: Incomplete information bargaining with filtered communication". mimeo, Universitat Autònoma de Barcelona, Institut d'Anàlisi Econòmica (CSIC) and University of Edinburgh, 2001.

J. A. Kennerley. Arbitration: Cases in Industrial Relations. Pitman Publishing, London, 1994.

P. Manzini and M. Mariotti. "Perfect Equilibria in a Model of Bargaining with Arbitration". Games and Economic Behavior, vol. 37 (1):170-195, 2001.

P. Manzini and C. Ponsatí. "Stakeholders, Bargaining and Strikes". IZA (Institute for 
Labour Economics, Bonn) Discussion Paper n. 395, 2001.

P. Manzini. "Divide et Impera: Negotiating with a Stakeholder". IZA (Institute for Labour Economics, Bonn) Discussion Paper 421 and Queen Mary Department of Economics Working Paper n. 451, 2001, 2001.

S. Milner. "Final-Offer Arbitration in the U.K.: Incidence, Processes and outcomes". Employment Department Research Series No. 7, 1993.

G. S. Morris. Strikes in essential services. Mansell Publishing, London and New York, 1986.

A. Muthoo. Bargaining Theory with Applications. Cambridge University Press, Cambridge, 1999.

M. Osborne and A. Rubinstein. Bargaining and Markets. Academic Press, San Diego, 1990.

M. A. Peña. "Concession Bargaining and Voluntary Arbitration". Unpublished Ph.D. Thesis, Universitat Autònoma de Barcelona, 2002.

C. Ponsatí. "Economic Diplomacy". mimeo, Universitat Autònoma de Barcelona, Institut d'Anàlisi Econòmica (CSIC), 2001.

A. Rubinstein. "Perfect Equilibrium in a Bargaining Model". Econometrica, 50:97-109, 1982.

C. Wilson. "Mediation and the Nash Bargaining Solution". mimeo, New York University), 2000. 


\section{IZA Discussion Papers}

\begin{tabular}{|c|c|c|c|c|}
\hline No. & Author(s) & Title & Area & Date \\
\hline 511 & $\begin{array}{l}\text { F. Büchel } \\
\text { H. Battu }\end{array}$ & $\begin{array}{l}\text { The Theory of Differential Overqualification: } \\
\text { Does it Work? }\end{array}$ & 1 & $06 / 02$ \\
\hline 512 & $\begin{array}{l}\text { C. Belzil } \\
\text { J. Hansen }\end{array}$ & $\begin{array}{l}\text { A Structural Analysis of the Correlated Random } \\
\text { Coefficient Wage Regression Model }\end{array}$ & 6 & $06 / 02$ \\
\hline 513 & $\begin{array}{l}\text { C. Belzil } \\
\text { J. Hansen }\end{array}$ & $\begin{array}{l}\text { Earnings Dispersion, Risk Aversion and } \\
\text { Education }\end{array}$ & 6 & $06 / 02$ \\
\hline 514 & F. Schneider & $\begin{array}{l}\text { The Size and Development of the Shadow } \\
\text { Economies of } 22 \text { Transition and } 21 \text { OECD } \\
\text { Countries }\end{array}$ & 4 & $06 / 02$ \\
\hline 515 & $\begin{array}{l}\text { J. Hurley } \\
\text { R. Vaithianathan } \\
\text { T. F. Crossley } \\
\text { D. Cobb-Clark }\end{array}$ & $\begin{array}{l}\text { Parallel Private Health Insurance in Australia: } \\
\text { A Cautionary Tale and Lessons for Canada }\end{array}$ & 3 & $06 / 02$ \\
\hline 516 & H. Bonin & $\begin{array}{l}\text { Eine fiskalische Gesamtbilanz der Zuwanderung } \\
\text { nach Deutschland }\end{array}$ & 7 & $06 / 02$ \\
\hline 517 & E. Tekin & $\begin{array}{l}\text { Child Care Subsidies, Wages, and Employment } \\
\text { of Single Mothers }\end{array}$ & 3 & $06 / 02$ \\
\hline 518 & $\begin{array}{l}\text { P. Carneiro } \\
\text { J. J. Heckman }\end{array}$ & $\begin{array}{l}\text { The Evidence on Credit Constraints in } \\
\text { Post-Secondary Schooling }\end{array}$ & 5 & $06 / 02$ \\
\hline 519 & $\begin{array}{l}\text { S. Cohen } \\
\text { Z. Eckstein }\end{array}$ & $\begin{array}{l}\text { Labor Mobility of Immigrants: Training, } \\
\text { Experience, Language and Opportunities }\end{array}$ & 1 & $06 / 02$ \\
\hline 520 & U. Sunde & $\begin{array}{l}\text { Unobserved Bilateral Search on the Labor } \\
\text { Market: A Theory-Based Correction for a } \\
\text { Common Flaw in Empirical Matching Studies }\end{array}$ & 1 & $06 / 02$ \\
\hline 521 & $\begin{array}{l}\text { U. Sunde } \\
\text { R. Fahr }\end{array}$ & $\begin{array}{l}\text { Employment Status, Endogenous Regional } \\
\text { Mobility, and Spatial Dependencies in Labor } \\
\text { Markets }\end{array}$ & 1 & $06 / 02$ \\
\hline 522 & $\begin{array}{l}\text { S.-Å. Dahl } \\
\varnothing . \text { A. Nilsen } \\
\text { K. Vaage }\end{array}$ & $\begin{array}{l}\text { Gender Differences in Early Retirement } \\
\text { Behaviour }\end{array}$ & 3 & $06 / 02$ \\
\hline 523 & $\begin{array}{l}\text { J. Falkinger } \\
\text { V. Grossmann }\end{array}$ & $\begin{array}{l}\text { Workplaces in the Primary Economy and Wage } \\
\text { Pressure in the Secondary Labor Market }\end{array}$ & 3 & $07 / 02$ \\
\hline 524 & $\begin{array}{l}\text { J. J. Dolado } \\
\text { F. Felgueroso } \\
\text { J. F. Jimeno }\end{array}$ & $\begin{array}{l}\text { Recent Trends in Occupational Segregation by } \\
\text { Gender: A Look Across the Atlantic }\end{array}$ & 2 & $07 / 02$ \\
\hline 525 & $\begin{array}{l}\text { J. J. Heckman } \\
\text { C. Heinrich } \\
\text { J. Smith }\end{array}$ & The Performance of Performance Standards & 6 & $07 / 02$ \\
\hline 526 & $\begin{array}{l}\text { E. Leuven } \\
\text { H. Oosterbeek }\end{array}$ & $\begin{array}{l}\text { A New Approach to Estimate the Wage Returns } \\
\text { to Work-Related Training }\end{array}$ & 6 & $07 / 02$ \\
\hline 527 & J. C. van Ours & The Locking-in Effect of Subsidized Jobs & 4 & $07 / 02$ \\
\hline 528 & $\begin{array}{l}\text { P. Manzini } \\
\text { M. Mariotti }\end{array}$ & $\begin{array}{l}\text { Arbitration and Mediation: An Economic } \\
\text { Perspective }\end{array}$ & 3 & $07 / 02$ \\
\hline
\end{tabular}

An updated list of IZA Discussion Papers is available on the center's homepage www.iza.org. 